\title{
Remembering Sherrie Reynolds
}

\author{
M. FRANCYNE HUCKABY \\ Texas Christian University (USA)
}

When I think of Dr. Sherrie Reynolds, my teacher, friend and colleague of nearly 25 years, her bold wisdom and quest for justice come to mind. At first individual remembrancesencouraging our faculty to consider longer-term consequences to our decisions, sharing a story of actions that made a difference, structuring experiences within communities into her classes, using stories to theorize - trickle from my memories of Sherrie. Rather quickly they pool into a collection that has depth like an abundant reservoir and a surface that ripples. For this reason, I find it difficult to think about Sherrie in the past tense. The lessons of her actions, thinking, and presence are very much in the here and now. Actually, much that she teaches asks us to move beyond the taken-for-grant that is to what should be. It's About Time, written with Julie Vu (one of Sherrie's doctoral students), is one example of the depth of Sherrie's wise storytelling, theorizing, teaching, and justice work.

A scholarship for curriculum studies graduate students now holds Sherrie Reynolds' name at Texas Christian University ( $\underline{h t t p: / / w w w . m a k e a g i f t . t c u . e d u})$. Additionally, the Chaos and Complexity Theories Special Interest Group (SIG) of the American Educational Research Association honors Sherrie with an award for the best graduate student paper. I invite your contributions to either or both of these funds as a way to honor Sherrie and her tireless support of graduate students. 